\title{
Outbreak of Kyasanur Forest Disease in Shivamogga, Karnataka State, India, during 2015
}

\author{
NB Thippeswamy ${ }^{1 *}$ SK Kiran ${ }^{2}$ \\ ${ }^{1}$ Department of post graduate studies and Research in Microbiology, Jnana Sahyadri campus, Kuvempu University, Shivamogga, Karnataka, India \\ ${ }^{2}$ Department of Health and Family Welfare, Shivamogga, Karnataka, India
}

Received: 09 February, 2017; Accepted: 13 March, 2017; Published: 23 March, 2017

*Corresponding author: NB Thippeswamy, Department of post graduate studies and Research in Microbiology, Jnana Sahyadri campus, Kuvempu University, Shivamogga, Karnataka, India, Tel: +91 9731728364; E-mail: nbtmicro@gmail.com

\begin{abstract}
KFD is a Tick born viral disease with seasonal outbreak between the months of December to May. The number of cases of Kyasanur Forest Disease was investigated in Karnataka state, India, during January to July 2015. Reported incidences in 2015 were relatively less with 124 suspected and 41 RT-PCR or IgM Elisa positive cases when compared to 400 suspected and 166 positive cases reported in 2014. Majority of suspected KFD cases (124) in 2015 were reported from Shivamogga District, with only few cases reported from remaining endemic districts of KFD and one death was recorded. The number of KFD cases reported every year even after regular vaccination program in its original endemic area. KFD spreads from the zone of first outbreak along the belt of Western Ghats continuously to the newer area. New diagnostic techniques for quick diagnosis and more effective and specific drug to treat KFD patients is the need of the hour in the light of available vaccine which is not so readily accepted by the people in the endemic area.
\end{abstract}

\section{Introduction}

Kyasanur Forest disease (KFD) is a tick-borne viral disease caused by Kyasanur Forest disease virus (KFDV), a member of the virus family Flaviviridae. Kyasanur Forest Disease was first discovered in 1956 in Kyasanur village of Soraba Taluk, Shivamogga District, Karnataka state, India [1]. The KFDV spreads to monkeys and human beings through the bite of infected ticks. It mainly infects two types of monkeys, one is black faced langurs (Semnopethicus entellus) and red faced bonnet monkeys (Macaca radiate) and various tick species (Genus Hemaphysalis). KFDV infected ticks spread the virus after feeding onto healthy monkeys. Uninfected ticks get the virus by feeding infected monkeys. KFDV infection causes severe febrile illness in monkeys. After the death of infected monkeys, ticks drop off from the body of the dead monkeys and create the danger zone or hot spots of infectious ticks which spread the virus further by infecting healthy animals. KFDV circulates in the forest through different hosts like, rodents, shrews, birds, and ticks [2]. KFDV infects human beings through the bite of infected ticks when the people enter the hot spot area of KFD. Infected individuals manifest symptoms of KFD like, high fever, headache, myalgia, bleeding from nasal cavity, throat, gingivae and gastrointestinal tract [3].
KFD was initially restricted to 5 districts, Shivamogga, Chikkamagalore, Uttara kannada, Dakshina kannada and Udupi, but Chamarajanagara, District of Karnataka state also reported for KFD during 2012-13 [4]. Usually, KFD cases were reported from December - May and there will be around 100-500 infections on an average every year [2]. Hence, the present work was conducted to study the epidemiological distribution of KFD outbreak during the year 2015 in Karnataka (State) and compare it with the KFD outbreak, 2014.

\section{Methodology \\ Preparation of Human samples}

Blood samples $(5 \mathrm{ml})$ were collected from the people reported to the primary health centres and Taluk hospitals of the affected area with the history of unexplained fever. Serum was separated from the blood samples after centrifugation at 3000rpm/15min. Serum samples were transported to National Institute of Virology (NIV) Pune, through Virus Diagnostic Laboratory (VDL), Shivamogga for the detection of etiologic agent KFDV.

\section{Preparation of Monkey samples}

Through the surveillance system (Field health workers, ASHA, Forest guards, Anganavadi workers, community leaders and sensitized individuals), we got the information about monkey deaths. We used the services of local veterinary surgeon to conduct autopsy at place of death itself and collect visceral samples. They are collected in sterilized test tubes and transported to NIV Pune through VDL, Shivamogga for the detection of etiologic agent KFDV.

\section{Preparation of Tick samples}

Ticks were collected from, villages with the history of KFD activity, villages within $10 \mathrm{~km}$ radius of places with previous history of KFD activity, places reported with unusual high number of fever cases and area reported for monkey's death. Ticks were collected with the help of KFD field station staff and district entomologist team in sterilized test tubes and transported to NIV, Pune via VDL, Shivamogga for the detection of etiologic agent of KFDV. All the samples were maintained at cold temperature between $4-8^{\circ} \mathrm{C}$ throughout the procedure. 
Human serum samples, monkey brain, liver, heart, lungs, kidney and tick pools were sonicated in $600 \mathrm{ml}$ of minimum essential media (GIBCO/ BRL, Life technologies, Grand Island, NY, USA) and $400 \mathrm{ml}$ of media was added to the homogenate, Tripure isolation reagent (Roche Diagnostics, Indianapolis, in USA) was used to perform RNA extraction as described by Mourya et al , [5]. Samples were tested for KFDV by nested reverse transcription PCR (RT-PCR) and real time RT-PCR as described by Mourya et al, [5]. Human serum samples were also tested for the presence of IgM antibody by Elisa method.

\section{Results and discussion}

Highest number of cases reported between January to April because of high temperature before the commencement of rainfall. In 2015, maximum number of KFD cases was found in January when compared to remaining months (Table 1).
41 out of 124 human samples were positive for KFDV and none of the 42 Monkey visceral samples and 158 tick pools was positive for KFDV (Table 1). In 2015, from January to July a total of 124 cases were suspected for KFD in 71 villages in Shivamogga district; laboratory testing confirmed only 41 were infected with KFDV from 21 villages. Nearly 81\% (more than 100 out of 124) of suspected cases observed in 2015 and $77 \%$ (307 out of 400) suspected cases in 2014 were reported only from Thirthahalli (Virus diagnostic laboratory, Shimoga) Taluk, Shivamogga district [6], whereas in other districts like Chikkamagaluru, Uttarakannada, Dakshinakannada and Udupi, number of cases were very less. With the available data we can say that Thirthahalli Taluk, Shivamogga district is the hot spot for KFD (Figure1). In 2015, number of reported cases were 41 reduced by $75 \%$ when compared to 166 in 2014 (Table 1). This data shows, spreading of the disease is continuous but number of KFD incidences were randomly distributed in the infected

Table 1: Data showed the incidences of Kyasanur Forest disease with month wise in Karnataka state for the year 2015.

\begin{tabular}{|c|c|c|c|c|c|c|c|c|}
\hline Month & $\begin{array}{l}\text { Total villages } \\
\text { reported }\end{array}$ & $\begin{array}{c}\text { Total villages } \\
\text { positive }\end{array}$ & $\begin{array}{l}\text { Total cases } \\
\text { reported }\end{array}$ & $\begin{array}{c}\text { Total cases } \\
\text { Positive }\end{array}$ & $\begin{array}{c}\text { Monkey } \\
\text { specimen } \\
\text { collected }\end{array}$ & $\begin{array}{c}\text { Monkey } \\
\text { specimen } \\
\text { positive }\end{array}$ & $\begin{array}{c}\text { Total ticks } \\
\text { collected }\end{array}$ & $\begin{array}{c}\text { Total ticks } \\
\text { positive }\end{array}$ \\
\hline January & 47 & 10 & 57 & 15 & 0 & 0 & 125 & 0 \\
\hline February & 9 & 5 & 38 & 12 & 6 & 0 & 2 & 0 \\
\hline March & 1 & 0 & 7 & 5 & 10 & 0 & 7 & 0 \\
\hline April & 2 & 3 & 8 & 3 & 0 & 0 & 7 & 0 \\
\hline May & 10 & 3 & 12 & 6 & 12 & 0 & 13 & 0 \\
\hline June & 2 & 0 & 2 & 0 & 0 & 0 & 1 & 0 \\
\hline July & 0 & 0 & 0 & 0 & 14 & 0 & 3 & 0 \\
\hline Total & 71 & 21 & 124 & 47 & 42 & 00 & 158 & 00 \\
\hline
\end{tabular}

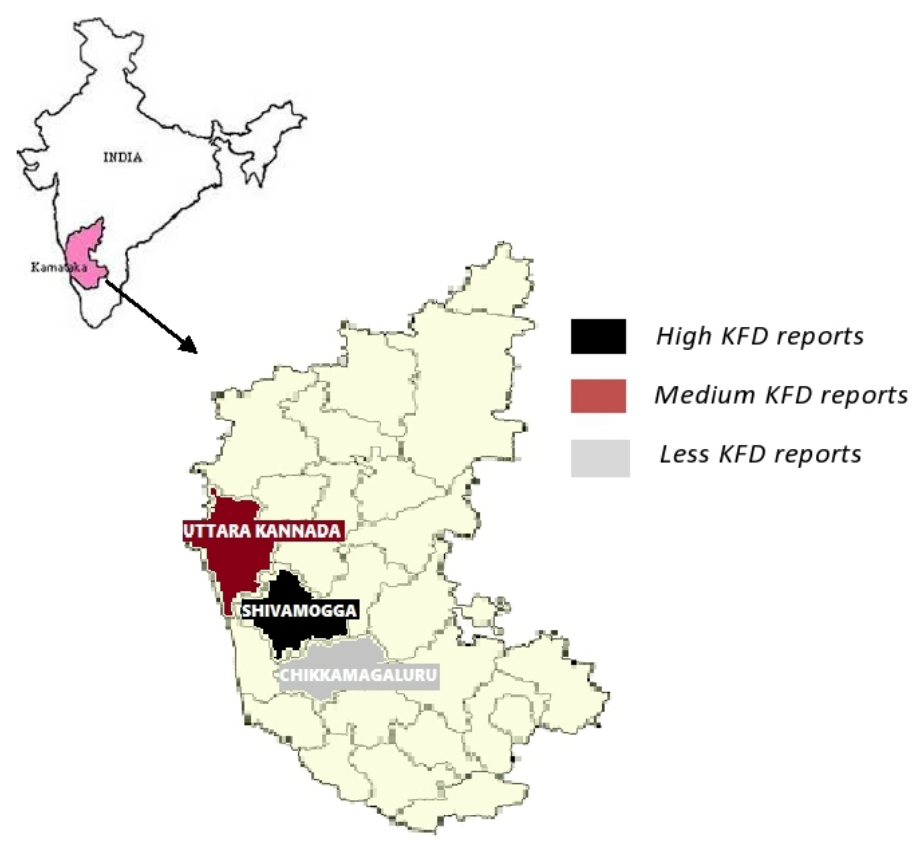

Figure 1: Map of India showing the rate of incidences reported in 3 different regions of Karnataka. 
area. The number of incidences of KFD differs with different districts, where Shivamogga district has more number of KFD cases compared to Uttarakannada and Chikkamagalur (Figure 2). Year wise, the number of incidences of KFD fluctuating very much, it shows the uncertainty of KFD cases in every year. In the year 2012, number of cases were 97, cases were reduced to 17 in 2013 whereas in 2014 positive cases increased to 166 and again reduced to 41 in 2015 (Table 2). We have also compared the data of KFD cases year wise from 2011-12 to 2014-15 as well as month wise (Figure 3). The graph clearly indicated the number of incidences of KFD were more from January-May, where increased temperature correlated with increased incidences of KFD. From the month of June no cases of KFD were found because of onset of monsoon during which ticks enter into non feeding phase of metamorphosis. It is very difficult to predict the place and time of KFD outbreak since 1956. The KFDV keeps on spreading towards north-west and south-west from the place of its discovery. To control mortality and morbidity of KFD following things needs to be done; development of quick diagnostic tool for the early and accurate diagnosis of the disease, discovery of drug to treat the patients of KFD and improvement of the efficacy of the current vaccine.

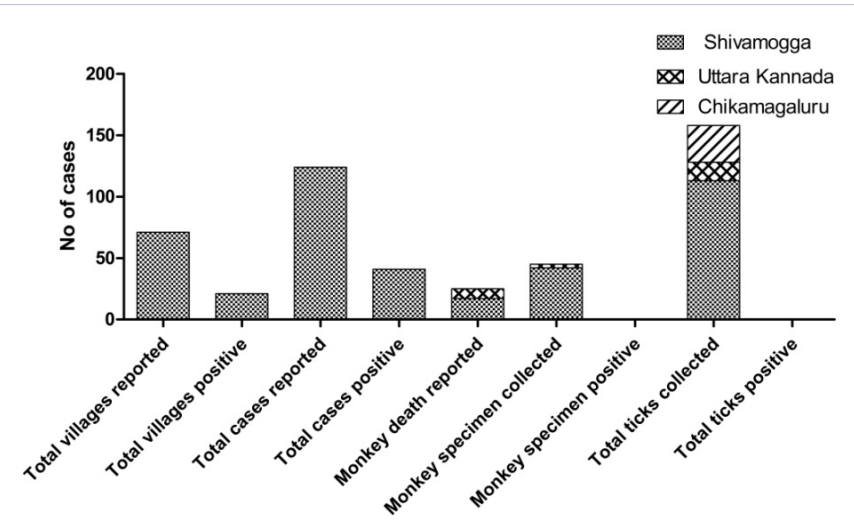

Figure 2: District wise incidence of Kyasanur forest disease in Karnataka state for the year 2015.

Table 2: Data showed the incidences of KFD cases, Monkeys death and tick pools from 2012-2015, Karnataka.

\begin{tabular}{|c|c|c|c|c|}
\hline Year & $\begin{array}{c}\text { Suspected } \\
\text { cases }\end{array}$ & $\begin{array}{c}\text { confirmed } \\
\text { cases }\end{array}$ & $\begin{array}{c}\text { Monkey } \\
\text { Deaths }\end{array}$ & $\begin{array}{c}\text { Tick Pools } \\
\text { collected }\end{array}$ \\
\hline 2012 & 359 & 97 & 64 & 239 \\
\hline 2013 & 82 & 17 & 50 & 290 \\
\hline 2014 & 400 & 166 & 31 & 262 \\
\hline 2015 & 124 & 41 & 41 & 176 \\
\hline
\end{tabular}

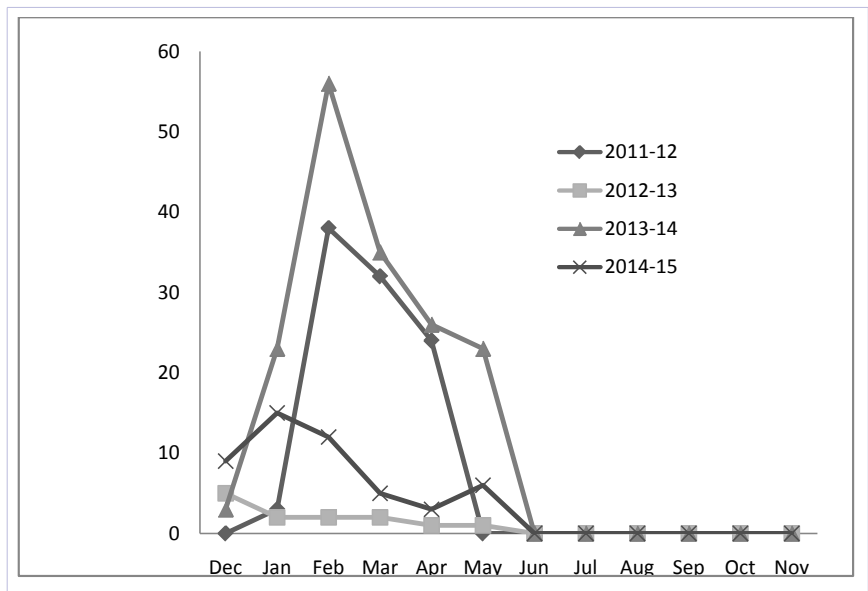

Figure 3: Month wise KFD cases from 2011-12 to 2014-15, in Karnataka state.

\section{Acknowledgments}

The authors are grateful to VGST, Karnataka for the financial assistance provided in conducting this study. We also gratefully acknowledge the assistance provided by Rajesh Suragihalli, District health and family welfare officer, Shivamogga; Dr. Ravikumar, Deputy director, Virus Diagnostic Laboratory, Shimoga; Sandhya V K, Microbiologist; Anand, Senior Laboratory technician, Virus Diagnostic Laboratory Shimoga and Dr. Mourya D.T, Director, National institute of virology, Pune.

\section{References}

1. Work TH, Roderiguez FM, Bhatt PN. Virological epidemiology of the 1958 epidemic of Kyasanur Forest Disease. Am J Public Health Nations Health. 1959;49(7):869-874.

2. Pattnaik P. Kyasanur Forest Disease: an epidemiological view in India. Rev Med Virol. 2006;16(3):151-165.

3. Dobler G. Zoonotic tick-born flaviviruses. Vet Microbiol. 2010;140(34):221-228. doi: 10.1016/j.vetmic.2009.08.024

4. Mourya DT, Yadav PD, Sandhya VK, Reddy S. Spread of Kyasanur Forest Disease, Bandipur Tiger Reserve, India, 2012-2013. Emerg Infect Dis. 2013;19(9):1540-1541. doi:10.3201/eid1909.121884

5. Mourya DT, Yadav PD, Mehla R, Barde PV, Yergolkar PN, Kumar SR et al. Diagnosis of Kyasanur Forest Disease by nested RT-PCR, real time RT-PCR and IgM capture ELISA. J Virol Methods. 2012;186(1-2):4954. doi: 10.1016/j.jviromet.2012.07.019

6. Yadav PD, Patil DY, Sanhya VK, Prakash KS, Surgihalli R, Mourya DT et al. Outbreak of Kyasanur Forest Disease in Thirtalli, Karnataka, India, 2014. Int J Infect Dis. 2014;26:132-134. doi: 10.1016/j. ijid.2014.05.013. 